\title{
Acute Magnesium Poisoning as a Complication of Chronic Intermittent Haemodialysis
}

\author{
J. R. GOVAN,* M.B., B.s. ; C. A. PORTER, $†$ M.B., в.S., D.oBst.R.C.o.G.; J. G. H. COOK, $\ddagger$ B.SC., M.I.BIOL. \\ BARBARA DIXON, $\S$ S.R.N. ; J. A. P. TRAFFORD,\| M.R.C.P.
}

Brit. med. F., 1968, 2, 278-279

Magnesium chloride is a normal constituent of dialysate solutions used for the haemodialysis of patients with end-stage renal disease. The concentration used in this centre is 1.5 $\mathrm{mEq} /$ litre. This communication describes the effects of an excessively high level of $15 \mathrm{mEg} / 1$. Previous to August 1967 our dialysate solutions were made up in the hospital dispensary as a 4-litre concentrate which was diluted to 120 litres with softened tap-water before use. The final solution is checked on a conductivity meter before beginning haemodialysis. In August 1967, owing to increasing demand on the hospital dispensary due to rapid growth in the size of the unit, we decided to obtain dialysate concentrates from a commercial supplier. Before using the new dialysate solution sodium, potassium, and chloride estimations were performed in our own laboratory. The public analyst later confirmed the above findings but also found that the diluted concentrate contained $15 \mathrm{mEq}$ of magnesium per litre. Six patients were dialysed for eight to nine hours with 1.45 or 0.9 Kolff-twincoils on the Baxter-Travenol R.S.P. with this abnormal dialysate.

\section{Clinical Observations}

After approximately three hours of dialysis the patients complained of a feeling of heat, mostly a burning sensation confined to the face. All complained of muscular weakness; half complained of blurring of vision and one of nausea.

On examination one patient, normally hypertensive, had a blood pressure of $130 / 90$; but blood pressure was unaffected in the others. None had an objective visual defect, but all showed objective loss of muscle power, together with abnormally brisk reflexes. Three patients were quite unable to stand unassisted and the others complained of ataxia.

After a further dialysis with our own dialysate concentrate, prepared in this hospital and known to have no ill effects or abnormalities from previous testing and use, all the patients had improved. They showed no further signs of weakness, ataxia, or hyperreflexia and no persisting disability was detected.

\section{Laboratory Investigations}

Estimation of calcium in serum and bath-water samples is carried out routinely for the renal dialysis unit by the method of Baron and Bell (1957). The titrant for this technique is an aqueous solution of disodium diamine-ethane-tetra-acetic acid, and the indicator a mixture of solid calcein and thymolphthalein. Under normal circumstances there is a rapid green to purple end-point, which in daylight with unhaemolysed non-icteric sera is not difficult to see.

During a batch of serum and bath-water calcium titrations it was noticed that, though the bath-water results were $5.4 \mathrm{mg}$./ $100 \mathrm{ml}$. as expected, some of the sera had abnormal end-points.

\footnotetext{
- Senior House Officer.

+ Registrar.

$\ddagger$ Registrar.

Sister.

I) Consultant Physician.

Renal Unit, Royal Sussex County Hospital, Brighton.
}

The colour change was not distinct and appeared to take place in two stages-the first from green to dirty grey, indicating a calcium level of between 8 and $10 \mathrm{mg} . / 100 \mathrm{ml}$., while the second stage, from dirty grey to purple, extended over a range of a further $14 \mathrm{mg} . / 100 \mathrm{ml}$., giving an apparent final " calcium " level of $24.1 \mathrm{mg} . / 100 \mathrm{ml}$. A further specimen of serum from the same patient was checked and a "calcium" level of 23.4 mg. found.

As clearly there was interference from an unknown source in the serum, it was decided to repeat the analysis with the oxalate precipitation method of Clark and Collip (1925). With this technique levels of 9.4 and $9.5 \mathrm{mg}$. of serum calcium per 100 ml. were obtained.

It was ultimately discovered that the cause of the interference was a gross excess of magnesium, which is normally not in sufficient quantity to affect this titration.

Unfortunately no magnesium analyses were carried out at the time when the serum levels were likely to have been at their highest, and only an approximate figure can be estimated from the known content of freely diffusible magnesium in the dialysate and the blood level interference.

\section{Discussion}

Hypermagnesaemia is an uncommonly diagnosed condition. It has been described after the use of magnesium sulphate as a purge in patients with renal failure. The normal range in plasma is 1.7 to $2.3 \mathrm{mEq} / \mathrm{l}$. (Elkington, 1957). Randall et al. (1964) conducted a series of experiments, studying the effects of intravenous magnesium on both normal subjects and patients with renal disease. They found that hypotension occurred at serum levels of $10 \mathrm{mEq} / 1$. They also noted that hypermagnesaemia had a depressive effect on the central nervous system at levels above $4 \mathrm{mEq} / \mathrm{l}$, causing drowsiness, lethargy, slight slurring of speech, ataxia, and a tendency to fall. In their series coma with diminished or absent tendon reflexes and diminished respirations occurred in one normal subject at serum concentrations above $10 \mathrm{mEq} / 1$. and in three patients with renal disease at concentrations greater than $7.5 \mathrm{mEq} / 1$.

Hypermagnesaemia has not been previously described as a complication of haemodialysis in humans, but dogs have been dialysed with a bath concentration of $20 \mathrm{mEq} / 1$. attaining plasma concentrations of $15 \mathrm{mEq} / 1$. (Grantham et al., 1960). This produced anaesthesia, slowing the pulse rate, minimal lengthening of the $\mathrm{P}-\mathrm{R}$ and $\mathrm{Q}-\mathrm{T}$ intervals, and progressive decline of the blood pressure.

Kelly et al. (1961) showed that rapid intravenous infusion of only a small amount of magnesium sulphate sufficient to raise the plasma level by less than $2 \mathrm{mEq} / 1$. caused a generalized vasodilatation, giving a sensation of warmth and flushing, a fall in blood pressure, and a rise in pulse rate.

The hypotension which occurs in hypermagnesaemia is presumably caused by the peripheral vasodilatation. This latter mechanism was probably responsible for the burning sensation which our patients experienced. The action of magnesium on the nervous system is twofold. Besides being a central depres- 
sant (Peck and Meltzer, 1916) it blocks transmission of neuromuscular impulses (Engbaek, 1952). This was demonstrated by the inability of our patients to maintain the erect position.

\section{Summary}

Six patients were accidentally dialysed against a dialysate containing an excessive amount of magnesium (15 mEq/1.).

Symptoms occurred of blurring of vision, flushing of the face, weakness, and inability to stand.

The high level of magnesium in the serum interfered with the usual laboratory method of serum calcium estimation, causing a false end-point to be observed.
The hypermagnesaemia was rapidly reversed by haemodialysis against a known normal dialysate fluid.

\section{Preliminary Communications}

\section{REFERENCES}

Baron, D. N., and Bell, J. L. (1957). Clin. chim. Acta, 2, 327.

Clark, E. P., and Collip, J.B. (1925). F. biol. Chem., 63, 461

Elkinton, J. R. (1957). Clin. Chem., 3, 319.

Engbaek, L. (1952). Pharmacol. Rev., 4, 396

Grantham, J. J., Tu, W. H., and Schloerb, P. R. (1960). Amer. F. Physiol., 198, 1211.

Kelly, H. G., Turton, M. R., and Hatcher, J. D. (1961). Canad. med. Ass. 7., 84, 1124.

Peck, C. H., and Meltzer, S. J. (1916). F. Amer. med. Ass., 67, 1131.

Randall, R. E., iun., Cohen, M. D., Spray, C. C., ;un., and Rossmeisl, E. C. (1964). Ann. intern. Med., 61, 73.

\section{Blood Base Changes after Secretion of Bicarbonate by Pancreas}

Brit. med. F., 1968, 2, 279-281

It has been demonstrated in man that the secretion of acid by the stomach is accompanied by a measurable increase of base in arterial blood provided that the acid is aspirated from the stomach or is neutralized by the ingestion of a meal (Rune, $1965,1966,1967)$. In these studies the amount of acid secreted was determined from arterial $\mathrm{pH}$ and $\mathrm{PCO}_{2}$ measurements. It was found that there was a correlation between the total acid secretion and the increase in base excess in arterial blood.

In the present study we have applied this principle to the study of pancreatic secretion, and we have shown that there is a fall in base excess when the pancreas secretes bicarbonate, if this is aspirated by means of a duodenal tube. The development of such methods could be of value in the study of normal and abnormal pancreatic function.

\section{THEORY OF METHODS}

When the pancreas secretes bicarbonate into the gastrointestinal tract as a result of secretin stimulation, if reabsorption is prevented it is likely that there will be a fall in the body stores of bicarbonate which will be reflected in a fall in the blood base value. An estimate of the amount of bicarbonate secreted into the gastrointestinal tract can be obtained from the blood base deficit and the volume of distribution of base:

$$
\begin{gathered}
\text { Pancreatic bicarbonate secre- } \\
\text { tion (mEq) (uncorrected). }
\end{gathered}=\begin{aligned}
& \Delta \text { Blood base }(\mathrm{mEq} / 1 .) \times \\
& \text { (litres). }
\end{aligned}
$$

The difference in blood base was taken as the difference between the mean pre-secretin base excess value and the mean post-secretin base excess value once a steady state had been reached. The base excess was calculated from the $\mathrm{PCO}_{2}$ and $\mathrm{pH}$ of the blood, and is a measure of the amount of nonvolatile base or acid, taking blood with a $\mathrm{PCO}_{2}$ of $40 \mathrm{~mm}$. $\mathrm{Hg}$ and a $\mathrm{pH}$ of 7.4 as zero. The normal range is -2.4 to +2.3 $\mathrm{mEq} / 1$. (Siggaard-Andersen, 1964).

Rune (1967) has shown in normal subjects that 60 minutes after the intravenous infusion of bicarbonate the volume of distribution was a function of the body weight. He calculated a mean coefficient of distribution of 0.28 per $\mathrm{kg}$. body weight. We have employed this factor in computing the volume of distribution of bicarbonate ; the volume from which bicarbonate was removed by pancreatic secretion.

Loss of base from the body is partly counterbalanced when the stomach secretes acid, there being an equivalent addition of bicarbonate to the body stores. In addition the kidney responds to the base deficit by excreting hydrogen ions into the urine and regenerating bicarbonate ions.

The corrected formula for the calculation of pancreatic bicarbonate secretion thus becomes:

Pancreatic bicarbonate secre- $\Delta$ Blood base $(\mathrm{mEq} / \mathrm{l}$ ) $\times$ tion $(\mathrm{mEq})=0.28 \times$ body weight $(\mathrm{kg}$. $)$. $+\mathrm{H}^{+}$secretion of stomach $(\mathrm{mEq})+\mathrm{H}^{+}$excretion of kidneys (mEq).

Respiratory compensation and the effects of other buffers are taken into account by using base excess as a measure of nonvolatile base.

\section{Procedure}

Seven patients were studied during routine testing of pancreatic function. In each patient the duodenum was intubated with a double-lumened Dreiling tube under radiological control. After a basal period of one hour the pancreas was stimulated with secretin (Boots) in a dosage of $3 \mathrm{u} . / \mathrm{kg}$. by intravenous injection, and the duodenal and gastric aspirates were collected separately for one hour. Gastric acid was titrated with $\mathrm{N} / 10 \mathrm{NaOH}$ to $\mathrm{pH} 7$ with a Beckman, model 72 , $\mathrm{pH}$ meter, and pancreatic bicarbonate secretion was measured by means of the Technicon AutoAnalyzer (method N-8b). The standard deviation for the bicarbonate estimations was $3 \mathrm{mEq} / \mathrm{l}$. Recovery studies were performed by adding a known amount of bicarbonate to each duodenal sample as soon as it was aspirated. Recovery varied between 90 and $100 \%$.

After intubation an adequate period of time was allowed for the establishment of a basal state, and during the procedure temperature variations in the room were kept to a minimum and every attempt was made to allay anxiety in the patient and to avoid hyperventilation.

The reason for the arterial puncture was explained to each patient and permission obtained before proceeding. Of the 